\title{
Hand Bionic Score: a clinical follow-up study of severe hand injuries and development of a recommendation score to supply bionic prosthesis
}

\author{
Dennis Werner ${ }^{1} \cdot$ Seyed Arash Alawi ${ }^{1}$ \\ Received: 10 March 2020 / Accepted: 22 April 2020 / Published online: 26 June 2020 \\ (C) The Author(s) 2020, corrected publication 2021
}

\begin{abstract}
Background Severe hand injuries significantly limit function and esthetics of the affected hand due to massive trauma in skeletal and soft tissues. Surgical reconstruction is often unsatisfactory, so bionic prostheses are a consideration. However, assessment of functional outcomes and quality of life after surgical reconstruction to guide clinical decisions immediately after injury and in the course of treatment remain difficult.

Methods We conducted a prospective follow-up analysis of patients with severe hand injuries during 2016-2018. We retrospectively evaluated initial trauma severity and examined current functional status, quality of life, general function, and satisfaction in everyday situations of the hand. We also developed a novel Hand Bionic Score to guide clinical recommendation for selective amputation and bionic prosthesis supply.

Results We examined 30 patients with a mean age of 53.8 years and mean initial severity of hand injury (iHISS) of 138.4. Measures indicated moderate quality of life limitations, moderate to severe limitation of overall hand function, and slight to moderate limitation of actual hand strength and function. Mean time to follow-up examination was 3.67 years. Using the measured outcomes, we developed a Hand Bionic Score that showed good ability to differentiate patients based on outcome markers. Appropriate cutoff scores for all measured outcome markers were used to determine Hand Bionic Score classifications to guide clinical recommendation for elective amputation and bionic prosthetic supply: $<10$ points, bionic hand supply not recommended; 10-14, bionic supply should be considered; or $>14$, bionic supply is recommended.

Conclusions While iHISS can guide early clinical decisions following severe hand injury, our novel Hand Bionic Score provides orientation for clinical decision-making regarding elective amputation and bionic prosthesis supply later during the course of treatment. The score not only considers hand function but also psychological outcomes and quality of life, which are important considerations for patients with severe hand injuries. However, future randomized multicenter studies are needed to validate Hand Bionic Score before further clinical application.

Level of evidence: Level III, risk/prognostic study.
\end{abstract}

Keywords Complex hand trauma $\cdot$ Amputation $\cdot$ Reconstructive surgery $\cdot$ Quality of life $\cdot$ Functional outcome $\cdot$ Bionic score Bionic prostheses

\section{Introduction}

Hand injuries represent the most frequent body part for workrelated injuries involving either crushing, fracture, or

Seyed Arash Alawi

s.a.alawi88@gmail.com

1 Department of Plastic, Aesthetic, Hand and Reconstructive Surgery, Hannover Medical School, Carl-Neuberg-Strasse 1, 30625 Hannover, Germany amputation, with a lifetime prevalence of injuries leading to hospitalization of $15-46 \%$ and annual prevalence of 5-30\% $[1,2]$. Injury mechanisms such as crush or high-voltage electrical injury can have devastating consequences, and degloving injuries can be mutilating [3-5]. Preservation of life as well as reconstruction of injured anatomical structures are the main medical aims following injury $[6,7]$. However, reconstructive surgery often does not lead to good function and esthetics even after months or years of surgical intervention. Furthermore, critical tissue damage can lead to significant limitations as well as pain that not only renders the affected 
limb useless but also turns it into a disabling appendage [8]. In the case of total or subtotal amputation, success of implantation and revascularization depends on duration of ischemia as well as accompanying injuries. Furthermore, outcomes especially depend on a surgeon's surgical skills [9, 10].

Severe hand injuries with mutilation of the hand or loss of functional parts can have physical, social, psychological, and economic consequences for the patient [11]. The role of one's own body image plays a special role in coping with trauma. Psychological effects of hand disfigurement can significantly outweigh functional impairment and disturb a patient's identity $[12,13]$. In addition, interpersonal perceptions of patients with bionic technologies can vary based on the technology [14]. Although the aim of reconstructive surgery is to restore esthetic and function by reconstructing anatomical structures, the reconstructive process is long and elaborate and may not result in the desired functionality and appearance [15].

Severity of disability due to hand injuries is determined by a patient's recognition of the loss and adaptability of body image, which is influenced by personality as well as social environment [16]. Hand injuries can imply high emotional burden for patients and can relate to long return-to-work times $[17,18]$. The most important prognostic factors for long return-to-work times after traumatic hand injuries are more severe impairment and low pre-injury income, while age, educational level, and gender do not seem to influence return-towork times [19, 20]. Furthermore, although prevalence of anxiety and depression decreases over the first 3 months after initial trauma, there is no significant change in their prevalence up to one-year follow-up [21]. In addition, mutilating hand injuries can be linked to stress and anxiety disorders as well as severe depression, pain syndromes, and adjustment problems. Patients with severe hand injuries experience symptoms associated with such disorders, including nightmares, flashback memories, mood swings, cognitive issues, scruples related to disfigurement, phantom limb sensation, and fear of dying. Flashbacks and nightmares are by far the most immediate post-injury symptoms and are considered key factors contributing to emotional distress in the early stages of traumatic hand injury [22]. In addition, reconstruction with repetitive operations adds additional focus on the disabled hand.

To avoid the long reconstruction process with possible unsatisfactory results, an alternative treatment option is early amputation and supply of a bionic prosthesis, although this option should be a mutual decision. Before bionic prostheses can become a primary medical supply choice after amputation, not only do technical problems need to be overcome but also criteria for valid clinical decision-making need to be developed [23]. However, clinical follow-up in patients with disseminated intravascular coagulopathy (DIC) and consecutive amputation followed by bionic prosthetic supply show sufficient to moderate results in function and quality of life [24]. The main reported reasons for non-application of prostheses are weight of the prosthesis, signal transmission disorders based on scarring of the skin, and repeated technical failures [24, 25].

Development of possible solutions for better signal transmission as well as smoother interfaces between human and machine are essential for prosthetic control. For patients with extensive stump scarring caused by internal diseases as well as burn traumata, implantable signal electrodes can improve signal transmission [26]. Furthermore, a combination of targeted muscle reinnervation (TMR) and implantable myoelectric sensors (IMES) can increase signal strength [27, 28]. IMES transmit electromyography (EMG) data wirelessly to the prosthesis and are inductively coupled via an external coil integrated in the prosthesis socket. Follow-up of three patients with transhumeral amputations demonstrated significant functional improvements of an implanted system over surface electrodebased control [27, 29]. While common myoelectric prostheses with surface EMG signals provide limited direct and intuitive control of the prosthesis, IMES-controlled prostheses provide very controlled EMG activity and more proportional and intuitive motion [30, 31].

For both acute massive injuries of hand function and multilevel injury and long-term surgical treatment, patients with severe hand injuries should be evaluated for potential selective amputation and myoelectric prosthetic supply, offering the potential of using technology to replace their lost function. However, no data currently correlates function and quality of life of patients with severe hand injuries to long-term outcome parameters after surgical reconstruction to guide treatment decisions. Therefore, we carried out a prospective, monocentric, non-randomized study to assess functional outcome parameters and quality of life for severe hand injuries and consecutive surgical reconstruction. Furthermore, we defined a scale for initial amputation and developed a novel Hand Bionic Score to guide clinical decision-making based on measurable outcome parameters in the course of treatment for amputation and bionic prosthesis supply.

\section{Material and Methods}

\section{Patients}

We conducted a monocentric, prospective follow-up analysis of 92 patients with severe hand injuries during 2016-2018. After telephone and written invitation, 30 patients provided written consent to participate in this study, for which we retrospectively evaluated initial trauma severity and performed clinical follow-up of current functional status, quality of life, and general function/satisfaction in everyday situations of the hand. Trauma severity was assessed by retrospective evaluation of photographic documentation with IMS (Imagic Bildverarbeitung AG, Glattbrugg, Switzerland) of severe 
hand injuries treated in our department of Plastic, Esthetic, Hand and Reconstructive Surgery.

Inclusion criteria were severe hand injury with soft tissue defects and massive injury to functional structures defined and based on initial Hand Injury Severity Score (iHISS). All patients provided written consent for participation in the study as well as publication of data and images. Approval for this study was granted by the Hannover Medical School (MHH) University Ethics Committee (\#7352). Research was conducted in accordance with the 1964 Helsinki Declaration.

\section{Functional status measures}

We assessed functional status using the German statutory accident insurance (Deutsche gesetzliche Unfallversicherung (DGUV)) measuring sheet for patients with hand, arm, and shoulder injuries. Mobility of joints was assessed by range of motion (ROM). Loss of function was calculated using ROM of the forearm, wrist, hand, and fingers compared with the uninjured hand [32]. We also measured hand strength using manometry and thumb strength using the pinch test.

\section{Quality of life measures}

Short Form 36 (SF-36): SF-36 is a disease-related measure to categorize health-related quality of life into eight subgroups.

Table 1 General statistics of study patients $(n=30)$

General statistics

\begin{tabular}{lll}
\hline & & $\mathrm{N}$ \\
\hline Gender & Female & 1 \\
& Male & 29 \\
& Total & 30 \\
Handedness & Both & 4 \\
& Left & 4 \\
& Right & 22 \\
Injured hand & Total & 30 \\
& Left & 16 \\
Dominant hand injury & Right & 14 \\
& Total & 30 \\
Changed job & Yes & 16 \\
& No & 14 \\
Profession-associated accident & Total & 30 \\
& No & 22 \\
& Yes & 8 \\
& Total & 30 \\
& No & 12 \\
& Yes & 18 \\
& Total & 30 \\
\hline
\end{tabular}

The score provides a general assessment by calculating values for physical and mental health subgroups and represents burden of disease. Scores range $0-100$ points, with 0 indicating the greatest restriction of health and low quality of life and 100 indicating absence of health restrictions and highest quality of life [33].

EuroQol-5 Dimensions Health-Questionnaire (EQ-5D$5 \mathrm{~L}$ ): EQ-5D-5 L is a descriptive system to quickly evaluate health-related quality of life with the following five subgroups: mobility, self-care, usual activities, pain/discomfort, and anxiety/depression. Each subgroup is classified into the following five levels: no problems, slight problems, moderate problems, severe problems, and extreme problems. This information can be converted into a one-dimensional index value and compared with normative values. Scores range $0-1$, with 0 indicating low and 1 indicating perfect health. Furthermore, patients rated their health on a visual analogue scale (EQ-5DVAS) from 0 to 100 [34].

\section{General hand function/satisfaction measures}

Disability of the Arm, Shoulder and Hand Score (DASH): DASH rates limitation and bimanual tasks in daily life and evaluates complaints and problems with everyday activities caused by the upper limb extremity with 30 questions. A score of 0 indicates the best hand function, while a score of 100 indicates the worst [35].

Michigan Hand Questionnaire (MHQ): MHQ evaluates hand function and satisfaction in patients with disabilities of the upper extremity. The survey consists of six scales evaluating overall hand function, activities of daily living, pain, work performance, esthetics, and patient satisfaction. An overall MHQ score can be obtained by summing all scales. A high score indicates better hand performance, while a low score indicates worse performance. Compared with DASH, MHQ provides a more detailed assessment of the disabled hand [36].

\section{iHISS}

Initial severity of hand injury was evaluated based on iHISS from earliest photographs of the injury. We retrospectively reviewed medical records in the electronic Systems Application Product (SAP) system (SAP Deutschland SE \& Co. KG, Walldorf, Rhein-Neckar, Version 22.10, Germany), which included photographs of the injury upon arrival in the operating room and notes of findings during operation. Based on this information, we calculated iHISS using a standard protocol [37]. An initial score of $<20$ is regarded as "minor" injury, 21-50 as "moderate" injury, 51-100 as "severe" injury, and > 100 as "major" injury [37]. Lower iHISS scores indicate lower severity with better functional outcome and hand strength, while higher scores indicate worse functional 
Table 2 Detailed descriptive statistics of all tests performed in this study

Descriptive statistics

\begin{tabular}{|c|c|c|c|c|c|c|c|}
\hline \multirow[t]{2}{*}{$N=30$} & \multirow[t]{2}{*}{ Mean } & \multirow[t]{2}{*}{ Median } & \multirow[t]{2}{*}{ SD } & \multirow[t]{2}{*}{ Minimum } & \multirow[t]{2}{*}{ Maximum } & \multicolumn{2}{|c|}{ Percentiles } \\
\hline & & & & & & 25 & 75 \\
\hline Age & 53.80 & 54.50 & 15.01 & 25 & 87 & 46.75 & 62 \\
\hline iHISS & 138.43 & 102.50 & 123.54 & 16.00 & 612 & 47.50 & 204.75 \\
\hline EQ-VAS & 74.33 & 80 & 17.89 & 20 & 100 & 65 & 87 \\
\hline EQ_5D-5L index value & 0.88 & 0.91 & 0.13 & 0.40 & 1 & 0.82 & 1 \\
\hline SF-36-physical functioning & 85.17 & 90 & 15.62 & 40 & 100 & 83.75 & 95 \\
\hline SF-36-role limitations due to physical health & 59.17 & 75 & 37.42 & 0 & 100 & 25.00 & 100 \\
\hline SF-36-role limitations due to emotional problems & 87.78 & 100 & 22.29 & 33.33 & 100 & 66.67 & 100 \\
\hline SF-36-energy/fatigue & 77.00 & 82.50 & 20.66 & 15 & 100 & 70 & 90 \\
\hline SF-36-emotional well-being & 83.47 & 84 & 13.23 & 40 & 100 & 75 & 96 \\
\hline SF-36-social functioning & 91.25 & 100 & 20.28 & 0 & 100 & 87.50 & 100 \\
\hline SF-36-pain & 79.33 & 95 & 28.02 & 10 & 100 & 65 & 100 \\
\hline SF-36-general health & 63.83 & 65 & 17.25 & 30 & 95 & 50 & 75 \\
\hline SF-36-total & 78.37 & 80.25 & 15.87 & 26.46 & 97.75 & 69.46 & 90.59 \\
\hline DASH & 23.58 & 15.83 & 19.58 & 0 & 66.67 & 8.96 & 29.58 \\
\hline MHQ-overall hand function & 52 & 55 & 19.10 & 10 & 85.00 & 38.75 & 66.25 \\
\hline MHQ-activities of daily living & 67.49 & 74.46 & 25.31 & 11.43 & 98.21 & 50.27 & 87.86 \\
\hline MHQ-work & 72.17 & 82.50 & 28.21 & 0 & 100 & 55 & 95 \\
\hline MHQ-pain & 19.33 & 5 & 25.38 & 0 & 85 & 0 & 37.50 \\
\hline MHQ-esthetic & 75.42 & 90.63 & 31.14 & 0 & 100 & 51.56 & 100 \\
\hline MHQ-satisfaction & 55.56 & 60.42 & 23.45 & 12.50 & 91.67 & 36.46 & 70.83 \\
\hline MHQ-total & 67.22 & 75.67 & 22.10 & 14.82 & 93.31 & 51.50 & 85.63 \\
\hline Manometry (\% loss of strength) & -40.65 & -40.47 & 26.22 & -88.52 & 0.67 & -62.09 & -22.68 \\
\hline Pinch test (\% loss of strength) & -31.12 & -20.53 & 30.16 & -100 & 12.50 & -52.78 & -7.77 \\
\hline Loss of sensibility (in mm) & -3.36 & -2.50 & 3.49 & -13 & 0.78 & -5.46 & -0.45 \\
\hline DGUV (\% loss of function) & -10.40 & -6.11 & 14.73 & -55.50 & 4.18 & -15.29 & -0.66 \\
\hline Time to follow -up & 3.67 & -3.40 & 2.13 & 0.57 & 11.34 & 2.02 & 4.80 \\
\hline
\end{tabular}

a

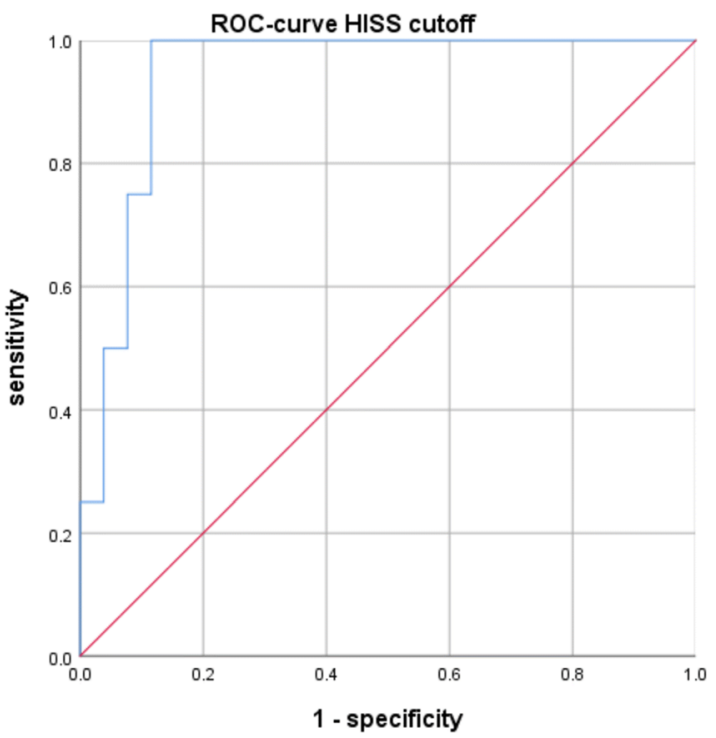

b

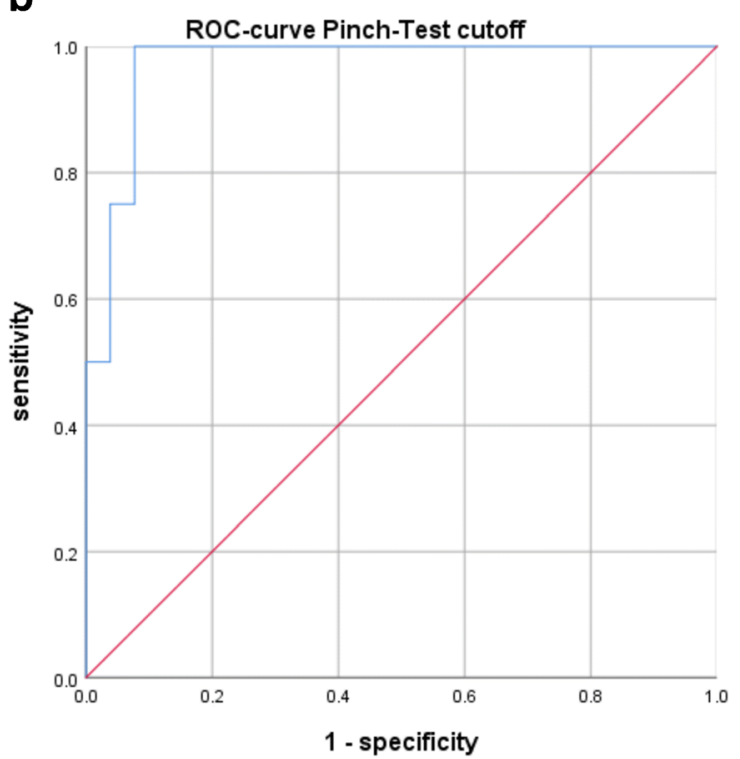

Fig. 1 ROC curves of cutoff values for a iHISS (cutoff $=206.5 ; J=0.885 ; \mathrm{AUC}=0.942)$ and $\mathbf{b}$ pinch test $(\operatorname{cutoff}=-61.81 ; J=0.923 ; \mathrm{AUC}=0.971)$ 
Table 3 Comparison of high and low cutoff values for all tests

\begin{tabular}{|c|c|c|c|c|c|c|}
\hline \multicolumn{7}{|c|}{ High cutoff value } \\
\hline & Cutoff value & Sensitivity & Specificity & Youden index & AUC & $95 \% \mathrm{CI}$ \\
\hline iHISS & 206.5 & $100 \%$ & $88.50 \%$ & 0.885 & 0.942 & $0.858-1$ \\
\hline DASH & 30.83 & $75 \%$ & $84.60 \%$ & 0.596 & 0.774 & $0.548-1$ \\
\hline MHQ & 65.56 & $100 \%$ & $69.20 \%$ & 0.692 & 0.798 & $0.624-0.972$ \\
\hline EQ-5D & 0.862 & $75 \%$ & $76.90 \%$ & 0.519 & 0.731 & $0.470-0.991$ \\
\hline SF-36 & 78.72917 & $75 \%$ & $69.20 \%$ & 0.442 & 0.788 & $0.563-1$ \\
\hline Manometry & -75.0945 & $75 \%$ & $96.20 \%$ & 0.712 & 0.913 & $0.785-1$ \\
\hline Pinch test & -61.8065 & $100 \%$ & $92.30 \%$ & 0.923 & 0.971 & $0.914-1$ \\
\hline \multicolumn{7}{|c|}{ Low cutoff value } \\
\hline & Cutoff & Sensitivity & Specificity & Youden index & AUC & $95 \% \mathrm{CI}$ \\
\hline iHISS & 114.5 & $84.60 \%$ & $82.40 \%$ & 0.67 & 0.882 & $0.764-1$ \\
\hline DASH & 22.5 & $76.90 \%$ & $82.40 \%$ & 0.593 & 0.819 & $0.657-0.981$ \\
\hline MHQ & 75.6746 & $84.60 \%$ & $76.50 \%$ & 0.611 & 0.846 & $0.708-0.984$ \\
\hline EQ-5D & 0.9095 & $69.20 \%$ & $58.80 \%$ & 0.28 & 0.681 & $0.482-0.880$ \\
\hline SF-36 & 78.72917 & $61.50 \%$ & $82.40 \%$ & 0.439 & 0.715 & $0.524-0.906$ \\
\hline Manometry & -47.958 & $69.20 \%$ & $88.20 \%$ & 0.574 & 0.769 & $0.572-0.966$ \\
\hline Pinch test & -39.0756 & $69.20 \%$ & $94.10 \%$ & 0.633 & 0.801 & $0.617-0.985$ \\
\hline
\end{tabular}

outcome and hand strength with higher injury severity [38-40]. Based on previous studies, iHISS can adequately predict functional outcome [39].

\section{Hand Bionic Score}

A manometry result of $<-70 \%$, pinch test result of $<-60 \%$, loss of two-point sensitivity discrimination of $>6 \mathrm{~mm}$, mean loss of motion of $>30^{\circ}$ compared with the unaffected hand, and amputation of at least three digits was considered a bad outcome in the long term and used for cutoff calculation with receiver operating characteristic (ROC) curves. To develop Hand Bionic Score cutoff values that can help decide whether to conduct a selective amputation and recommend a bionic prosthesis, we established two cutoffs. Patients with at least three of the above outcome markers were used to develop an upper cutoff value, while patients with at least one match were used to calculate a lower cutoff value. After grouping, we classified the respective groups by ROC curves. To define Hand Bionic Score cutoff values, Youden index $(J)$ and area under the curve (AUC) were calculated (values, 0-1). Higher Youden index indicates higher sensitivity and specificity of each cutoff value [41]. Cutoff values were then assigned points of 0-3 and were used to calculate Hand Bionic Score.

\section{Statistics}

For statistical analysis, data were converted into an SPSS database (IBM SPSS Statistics, Version 26.0). Descriptive metrics and their deviations ( $95 \%$ confidence interval, alpha level of 0.05 ) were generated. Significance between positive Hand
Bionic Score $(\geq 10)$ and negative score $(<10)$ groups was tested with the Mann-Whitney $U$ test due to non-parametric distribution, and the effect size $r$ was determined.

\section{Results}

\section{General data}

We examined 30 patients (29 males, 1 female; Table 1) with a mean age of 53.8 years (Table 2). Most accidents were associated with professional activities $(n=18)$, and eight patients subsequently changed their jobs (Table 1). Mean iHISS was 138.43, corresponding to major injury. Average EQ-5D-5 L was 0.88, and average SF-36 was 78.37, indicating moderate quality of life limitations. Mean DASH was 23.58, indicating moderate hand function; mean MHQ was 67.22, indicating moderate to severe limitation of overall hand function. Mean loss of function by DGUV was $-10.4 \%$, mean loss of strength by manometry was $-40.65 \%$, mean loss of strength by pinch test was $-31.12 \%$, and mean loss of sensitivity was $-3.36 \mathrm{~mm}$, showing slight to moderate limitation of actual hand strength and function. Mean time to follow-up examination was 3.67 years (Table 2).

\section{Hand Bionic Score}

Of the 30 examined patients, four had at least three of the above mentioned outcome markers, which were used to calculate upper cutoff values for Hand Bionic Score. In addition, 
Fig. 2 Hand Bionic Score sheet

\begin{tabular}{|c|c|c|c|}
\hline \multicolumn{4}{|c|}{ Hand Bionic Score Sheet } \\
\hline Test & Cutoff & Points & Result \\
\hline iHISS & $\begin{array}{l}<115 \\
115 \text { to } 206 \\
\geq 207\end{array}$ & $\begin{array}{l}0 \\
1 \\
3\end{array}$ & \\
\hline DASH & $\begin{array}{l}<22.5 \\
22.5 \text { to } 30.82 \\
\geq 30.83\end{array}$ & $\begin{array}{l}0 \\
1 \\
3\end{array}$ & \\
\hline MHQ & $\begin{array}{l}>75.68 \\
75.68 \text { to } 65.57 \\
\leq 65.56\end{array}$ & $\begin{array}{l}0 \\
1 \\
3\end{array}$ & \\
\hline EQ-5D & $\begin{array}{l}>0.9095 \\
0.9095 \text { to } 0.861 \\
\leq 0.862\end{array}$ & $\begin{array}{l}0 \\
1 \\
3\end{array}$ & \\
\hline SF-36 & $\begin{array}{l}>78.73 \\
\leq 78.73 \\
\end{array}$ & $\begin{array}{l}0 \\
1\end{array}$ & \\
\hline $\begin{array}{c}\text { Manometry } \\
\text { (\%) }\end{array}$ & $\begin{array}{l}>-47.96 \\
-47.96 \text { to }-75.09 \\
\leq-78.1\end{array}$ & $\begin{array}{l}0 \\
1 \\
3\end{array}$ & \\
\hline $\begin{array}{l}\text { Pinch-test } \\
\text { (\%) }\end{array}$ & $\begin{array}{l}>-39.08 \\
-39.08 \text { to }-61.8 \\
\leq-61.81\end{array}$ & $\begin{array}{l}0 \\
1 \\
3 \\
\end{array}$ & \\
\hline & & Total & \\
\hline Han & Bionic Scor & lassif & \\
\hline $0-9$ points & Bionic su & is not $r$ & ided \\
\hline $10-14$ points & Bionic supp & omes int & eration \\
\hline $15-19$ points & Bionic & oly is rec & \\
\hline
\end{tabular}

13 study participants had at least one matching outcome marker and were used to calculate lower cutoff values. The following upper cutoffs were determined from classification by ROC curves: iHISS of $206.5(J=0.885$; AUC $=0.942)$ (Fig. 1a), manometry test of $-75,09 \%(J=0.712$; AUC $=$ $0.913)$, and pinch test of $-61.8 \%(J=0.923$; AUC $=0.971)$ (Fig. 1b). Each cutoff showed high sensitivity and specificity. Furthermore, AUC indicated that these parameters were very good in distinguishing between groups with at least three outcome markers. Furthermore, cutoff values for DASH of $30.83(J=0.596$; AUC $=0.774)$, MHQ of 65.56 $(J=0.692$; AUC $=0.798)$, EQ-5D of $0.862 \quad(J=0.519$; $\mathrm{AUC}=0.731)$, and SF-36 of $78.73(J=0.442$; $\mathrm{AUC}=$ 0.788) had moderate Youden index with moderate AUC (Table 3, Fig. 2). These cutoffs provide moderate separation yet safe differentiation between patients with or without recommendation for upper limb prosthetic. For Hand Bionic Score, three points were assigned to all cutoffs except SF36 , because it represented no significant difference between lower and upper cutoffs.

The group with at least one matching outcome parameter was used to calculate a lower cutoff with the following values: iHISS of $114.5(J=0.67$; AUC $=0.882)$, DASH of $22.5(J=$ 0.593 ; $\mathrm{AUC}=0.819)$, MHQ of $75.67(J=0.611$; $\mathrm{AUC}=$ $0.846)$, EQ-5D of $0.9095(J=0.28$; $\mathrm{AUC}=0.681), \mathrm{SF}-36$ of $78.73(\mathrm{~J}=0.439$; AUC $=0.715)$, manometry of $-47.96 \%$ $(J=0.574 ; \mathrm{AUC}=0.769)$, and pinch test of $-39.08 \%(J=$ 0.633 ; AUC $=0.801$ ) (Table 3$)$. Youden index presented satisfactory to moderate sensitivity and specificity in every test, while AUC indicated moderate to good separation of this 

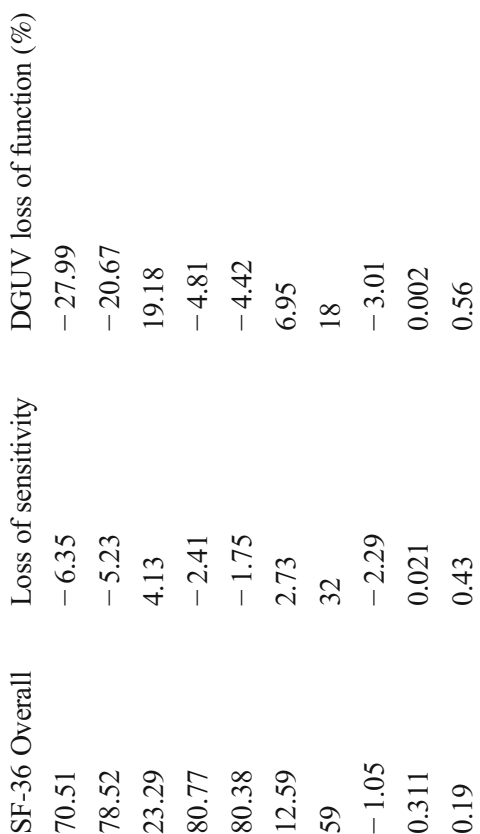

苛

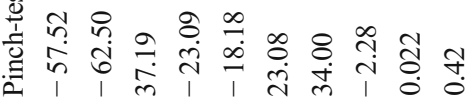

8

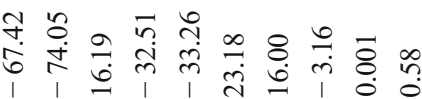

in

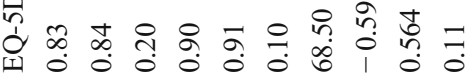

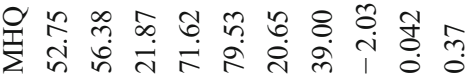

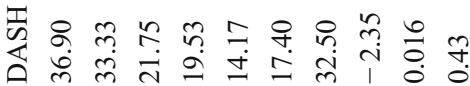

थ in

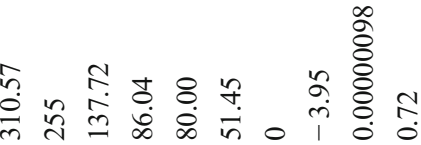

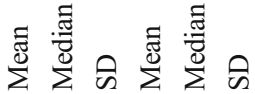

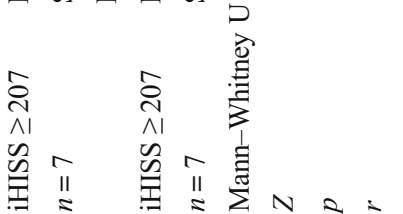

group. For score development, each value was assigned a Hand Bionic Score. After cutoff calculation, a Hand Bionic Score sheet was developed with the following classifications: 0-9 points, bionic hand prosthesis supply not recommended; 10-14 points, should consider bionic supply; > 14 points, bionic supply is recommended (Fig. 2).

After determining the upper cutoff value, iHISS of $>207$ indicated significant differences in all tests of the Hand Bionic Score except quality of life (EQ-5D, $p=0.564$; SF-36, $p=$ 0.311 ) compared with patients with an iHISS of $<207$. This shows that acute assessment of quality of life is difficult, so decisions regarding possible prosthetic supply must be weighed very carefully. Patients with an iHISS of $\geq 207$ have a mean loss of function of $-27.99 \%$ and loss of sensitivity of $-6.35 \mathrm{~mm}$, which represents a worse functional outcome. This is especially confirmed in the results of manometry (mean $(\mathrm{x})=-67.42 \%$; median $(\mathrm{x})=-74.05 \%)$, pinch test $(\mathrm{x}=-57.52 \% ; \mathrm{x}=-62.5 \%)$, and functional outcome scores (DASH, $\bar{x}=36.9 ; \mathrm{x}=33.33 ; \mathrm{SD}=21.75 ; \mathrm{MHQ}, \overline{\mathrm{x}}=52.75$; $\mathrm{x}=56.38 ; \mathrm{SD}=21.87)($ Table 4$)$.

\section{Hand Bionic Score of $<10$}

In the study cohort, 21 patients had a Hand Bionic Score of $<10$, resulting in no recommendation for a bionic prosthetic supply. These patients presented a mean loss of function of $5.44 \%$, which hardly represents restrictions in ROM. Patients had an average manometry loss of strength of $-28.29 \%$, average pinch test loss of strength of $-18.43 \%$, and average loss of sensitivity of $-2.53 \mathrm{~mm}$, indicating slight to moderate restrictions in hand strength and sensitivity (Table 5). Nonetheless, overall SF-36 $(\bar{x}=85.25)$ and EQ-5D ( $\bar{x}=$ 0.94 ) indicated only slight impairment of quality of life. Functional outcome and satisfaction as measured with DASH ( $=13.89)$ and MHQ ( $=77.69)$ were good to moderate, even considering that one patient had a MHQ score of 32.5 , although this result still did not indicate prosthetic supply. Patients had a mean iHISS of 93.86, corresponding to severe hand injury, although these patients had no indication for prosthetic care because not only injury pattern but also quality of life and functional tests contribute to decision-making. As a whole, these patients had a mean Hand Bionic Score of 2.19, and follow-up examination took place on average after 3.34 years $(\mathrm{x}=3.08$; range, $0.88-6.31$; $\mathrm{SD}=1.37)$.

\section{Hand Bionic Score of $\geq 10$}

In the study cohort, 9 patients with a Hand Bionic Score of $\geq$ 10 presented a mean loss of function of $-23.43 \%$, mean manometry loss of strength of $-69.51 \%$, and pinch test loss of strength of $-60.74 \%$, significantly corresponding to very low functional outcome compared with low-score patients (iHISS, $p<0.01$; DASH, $p<0.01$; MHQ, $p<0.01$; EQ-5D, $p<0.01$; 
Table 5 Descriptive statistics and comparison of patients with Hand Bionic Score of $<10$ or $\geq 10$

\begin{tabular}{|c|c|c|c|c|c|c|c|c|c|c|}
\hline \multicolumn{11}{|c|}{ Hand Bionic score $<10$} \\
\hline$n=21$ & iHISS & DASH & MHQ & EQ-5D & $\begin{array}{l}\text { SF-36 } \\
\quad \text { overall }\end{array}$ & Manometry $(\%)$ & Pinch test $(\%)$ & $\begin{array}{l}\text { Loss of } \\
\quad \text { sensitivity (mm) }\end{array}$ & $\begin{array}{l}\text { DGUV loss of } \\
\text { function (\%) }\end{array}$ & $\begin{array}{l}\text { Hand Bionic } \\
\text { Score }\end{array}$ \\
\hline Mean & 93.86 & 13.89 & 77.69 & 0.94 & 85.25 & -28.29 & -18.43 & -2.53 & -5.44 & 2.19 \\
\hline Median & 73 & 13.33 & 80.91 & 0.91 & 85.88 & -30.96 & -17.65 & -1.90 & -3.720 & 1.00 \\
\hline SD & 78.50 & 8.48 & 15.10 & 0.06 & 9.14 & 19.39 & 19.28 & 2.74 & 7.13 & 2.32 \\
\hline Minimum & 16 & 0 & 32.50 & 0.79 & 64.88 & -63.57 & -61.11 & -9.00 & -19.72 & 0 \\
\hline Maximum & 328 & 28.33 & 93.31 & 1 & 97.75 & 0.67 & 12.50 & 0.78 & 4.18 & 8 \\
\hline 25 Percentile & 45 & 7.50 & 73.71 & 0.91 & 79.88 & -41.96 & -33.33 & -3.20 & -10.43 & 0 \\
\hline 75 Percentile & 111 & 21.67 & 89.10 & 1 & 91.38 & -11.58 & -5 & -0.70 & 0.41 & 4 \\
\hline \multicolumn{11}{|c|}{ Hand Bionic Score $\geq 10$} \\
\hline$n=9$ & iHISS & DASH & MHQ & EQ-5D & $\begin{array}{l}\text { SF-36 } \\
\quad \text { Overall }\end{array}$ & Manometry (\%) & Pinch test (\%) & $\begin{array}{l}\text { Loss of } \\
\quad \text { sensitivity (mm) }\end{array}$ & $\begin{array}{l}\text { DGUV loss of } \\
\text { function (\%) }\end{array}$ & $\begin{array}{l}\text { Hand Bionic } \\
\text { Score }\end{array}$ \\
\hline Mean & 242.44 & 46.20 & 42.78 & 0.75 & 62.34 & -69.51 & -60.74 & -5.52 & -23.43 & 14.67 \\
\hline Median & 210.00 & 55 & 47.34 & 0.80 & 63.94 & -74.05 & -66.67 & -5.24 & -18.87 & 15 \\
\hline SD & 150.09 & 19.69 & 15.52 & 0.16 & 17.06 & 14.59 & 30.97 & 4.45 & 21.32 & 2.78 \\
\hline Minimum & 118 & 14.17 & 14.82 & 0.40 & 26.46 & -88.52 & -100 & -13 & -55.50 & 10 \\
\hline Maximum & 612 & 66.67 & 61.69 & 0.93 & 82.56 & -50.35 & -1.96 & -0.08 & 3.32 & 19 \\
\hline 25 Percentile & 135 & 28.33 & 30.36 & 0.67 & 52.73 & -82.48 & -84.62 & -9.06 & -43.95 & 13 \\
\hline 75 Percentile & 265.50 & 64.17 & 55.07 & 0.83 & 75.51 & -54.88 & -39.08 & -1 & -5.66 & 17 \\
\hline \multicolumn{11}{|c|}{ Comparison of Hand Bionic Scores of $<10$ and $\geq 10$} \\
\hline & & iHISS & DASH & MHQ & EQ-5D & SF-36 overall & Manometry & Pinch-test & Loss of sensitivity & $\begin{array}{l}\text { DGUV loss } \\
\text { of function }\end{array}$ \\
\hline \multicolumn{2}{|c|}{ Mann-Whitney U } & 21 & 14.50 & 12.00 & 16 & 8.00 & 15.00 & 22 & 48 & 38.00 \\
\hline \multicolumn{2}{|l|}{$z$} & -3.33 & -3.62 & -3.73 & -3.58 & -3.91 & -3.60 & -3.28 & -1.76 & -2.24 \\
\hline \multicolumn{2}{|l|}{$p$} & 0 & 0 & 0 & 0 & 0 & 0 & 0 & 0.08 & 0.02 \\
\hline \multicolumn{2}{|l|}{$r$} & 0.61 & 0.66 & 0.68 & 0.65 & 0.71 & 0.66 & 0.60 & 0.33 & 0.42 \\
\hline
\end{tabular}

SF-36 overall, $p<0.01$; loss of sensitivity, $p=0.08$; DGUV, $p=0.02$; manometry, $p<0.01$; pinch test, $p<0.01$ ) (Table 5). Furthermore, effect size indicated a strong effect in separating groups with different cutoffs, although average loss of sensitivity was not significant. Follow-up examination took place on average after 4.42 years $(x=3.66$; range, 0.57-11.34; $\mathrm{SD}=$ 3.3). Compared with patients with Hand Bionic Score of < 10, follow-up examination took place around the same mean time, although standard deviation greatly differed. Ultimately, there were clear differences between patients with high $(\geq 10$ points) or low (<10 points) Hand Bionic Scores (Fig. 3).

\section{Quality of life}

EQ-5D-5 L had a mean value of $0.75(\mathrm{x}=0.8 ; p<0.05)$ and effect size of $r=0.65$. SF-36 showed the biggest restrictions in subsections "role restrictions due to physical health" $(\mathrm{x}=27.78$; $\mathrm{x}=25$; range, $0-75)$, "pain" $(\mathrm{x}=52.22 ; \mathrm{x}=57.5$; range, 10 $100)$, and "general health" $(\mathrm{x}=56.67 ; \mathrm{x}=60$; range, 35-85). Mean total SF-36 score of $62.34(\mathrm{x}=63.94 ; p<0.05 ; r=0.71)$ indicated rather moderate to bad quality of life (Table 5). Nevertheless, these values showed significant differences between groups, particularly very good effect size of SF-36, indicating that these tests are very well-suited to determine a bionic supply recommendation. Especially for SF-36, role limitations due to injury and self-perception are central issues.

\section{Functional outcome}

Mean DASH score was $46.2(x=55 ; \mathrm{SD}=19.69)$ and mean overall MHQ score was $42.78(\mathrm{x}=47.34$; $\mathrm{SD}=15.52)$, indicating worse functional outcome (Table 5). Even years after reconstruction and surgical approach, hand function was not sufficient and patients were not satisfied. To evaluate Hand Bionic Score, these tests showed significant results (MHQ, $p<0.05 ; r=0.68$; DASH, $p<0.05 ; r=0.66)$ and had good effect intensity levels, indicating they were well-suited as decision parameters (Table 5). Furthermore, there was a significant positive Pearson correlation between Hand Bionic Score and MHQ (Fig. 4).

\section{iHISS}

Mean iHISS was $242(\mathrm{x}=210 ; \mathrm{SD}=150.09)$, corresponding to major hand injuries. Mann-Whitney $U$ test showed that differences between individual groups were significant. An 


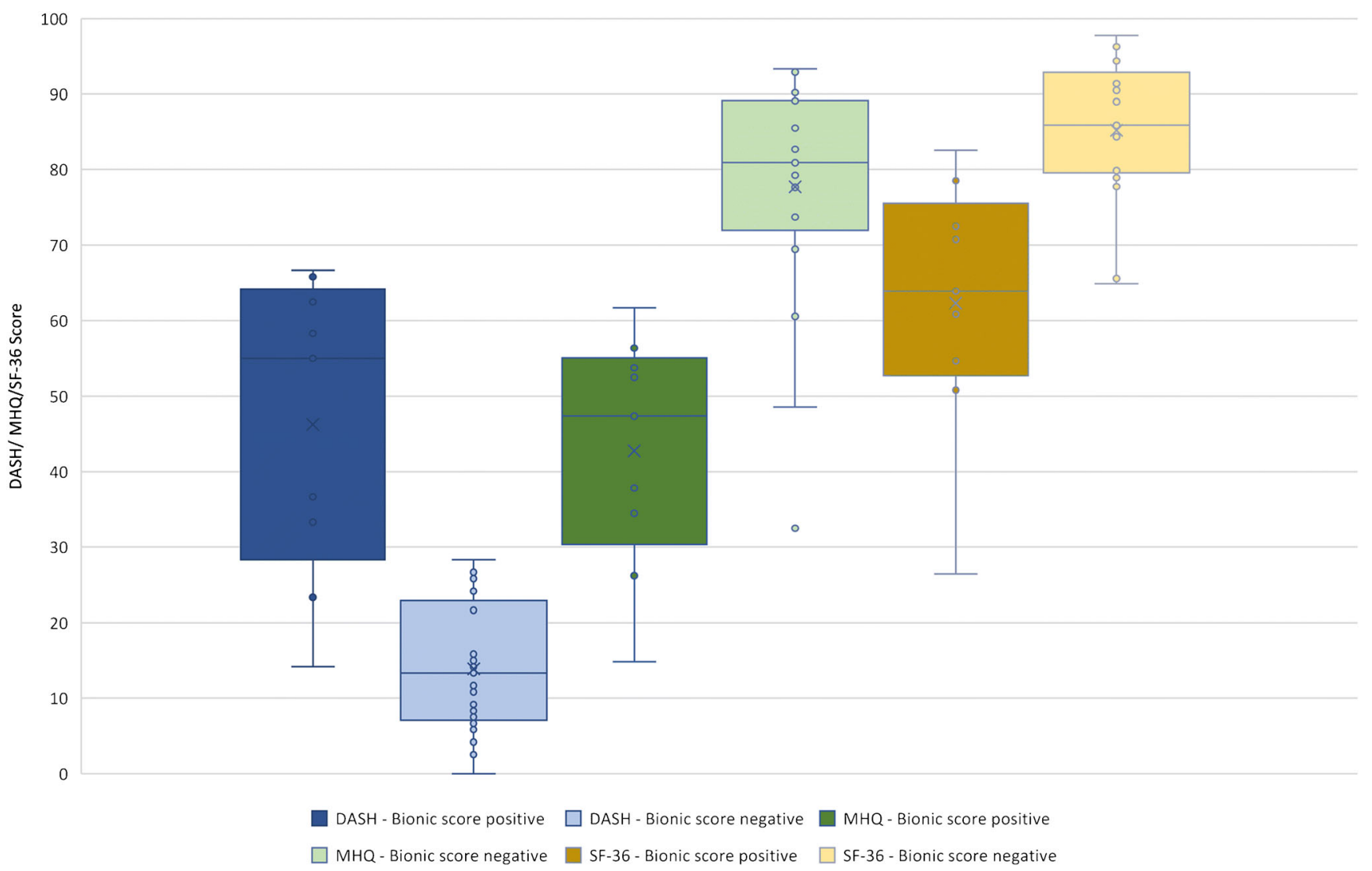

Fig. 3 Boxplots of differences in DASH, MHQ, and SF-36 scores between patients with Hand Bionic Scores of $\geq 10$ points (positive) or $<10$ points (negative)

iHISS of 115 indicates an initial consideration of prosthetic supply, while a score of $>207$ recommends an initial amputation and early prosthetic fitting and supply. Each individual test of the Hand Bionic Score showed a high to very high effect size as well as significant differences when comparing groups with scores of $<10$ and $\geq 10$ points (Table 5 ).

Figure 5 shows an example of a patient after severe hand injury with a Hand Bionic Score of 17 , indicating a recommendation for bionic prosthetic supply. Figure 6 shows another example of a patient after severe hand injury (iHISS $=276$ ) with poor to very poor quality of life and hand function, for which a Hand Bionic Score of 19 also recommends a bionic prosthesis fitting with amputation of the non-functioning hand.

\section{Discussion}

Functionality of the hand as well as results of reconstructive surgery is significantly related to the initial hand injury trauma event and extent of the injury. Multi-site injuries, bruises with marked tissue ischemia, consequent microcirculatory disturbances, and amputation or destruction of functional tissue represent worst outcomes [39, 42, 43]. In the event of a dissatisfied functional and esthetic reconstruction result [10], selective amputation and bionic prosthetic supply may relieve the patient from the destructive and disabling limb. However, whether to make an early amputation to prepare the stump for bionic prosthesis or to reconstruct defects for a long surgical and rehabilitation program are difficult clinical decisions to make.

Biological reconstruction of destroyed and traumatized tissue in the upper limb continues to be a top priority in hand surgery, although assessment of an injury and its predictable outcomes remain difficult. Clear perfusion damage of the tissue and lack of possible revascularization are hard criteria for amputation of the affected tissue. However, for areas that have suffered massive damage but are eligible for preservation, it is difficult to decide whether early amputation and bionic prosthetic care will benefit with shorter inpatient stay, interval for outpatient follow-up, and time to reintegration in professional life [15]. In addition to post-traumatic stress disorder associated with acute hand trauma, the need for repetitive corrective interventions also causes other psychological disorders such as anxiety, depression, and social isolation caused by disfigurement and pain [43-46].

Due to these psychological impairments in addition to restriction of social interactions, the ability to perform everyday tasks as well as the ability to work is limited mainly by altered self-image as well as feelings of self-worth [47-49]. From a 


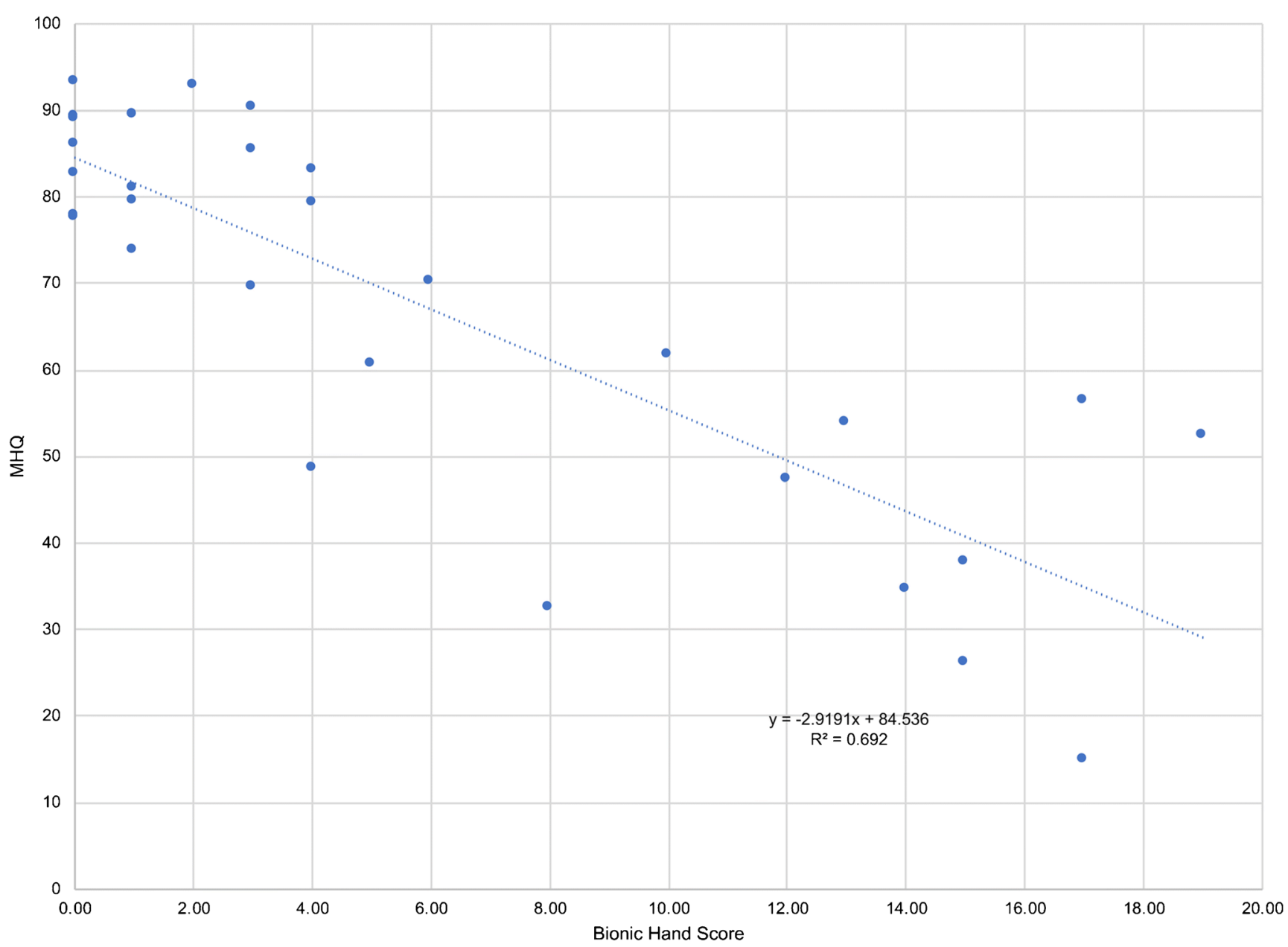

Fig. 4 Correlation of Hand Bionic Scores $(\bar{x}=5.9 ; \mathrm{x}=3.5, \mathrm{SD} \pm 6.3)$ with MHQ $\left(r=0.832 ; \mathrm{R}^{2}=0.692\right)$

psychological point of view, there is no significant disadvantage to amputation after failure of limb salvage, whereby prosthetic adaptation and restoration of body integrity and selfimage offer significant benefits $[43,50,51]$. Thus, the definition of failure of a surgical reconstruction has to be discussed and recorded on the basis of objectively measurable values. If a non-functioning limb remains despite surgical reconstruction, definitive intensive discussion and sufficient reflection time of the patient is necessary to plan a selective amputation and bionic prosthesis supply. This decision should be taken within a reasonable timeframe to avoid chronification of pain syndromes or further damage to posture due to wrong strain on movement.

We calculated iHISS of previous cases and correlated it with our Hand Bionic Score to orient previous cases where early amputation and bionic preparation could be recommended. A major difference is that Hand Bionic Score includes different modalities and values that provide an indication for selective amputation and bionic prosthesis supply based on functional and psychological outcomes. We propose iHISS evaluation as a valuable tool to decide very early in trauma if patients should go through biological reconstruction or receive early amputation and bionic prosthetic supply. If patients initially decide on reconstruction but do not adjust to hand function or quality of life, then Hand Bionic Score can be a valuable as a decision-making tool for subsequent

Fig. 5 Patient 1. a The patient had an accident as a motorcyclist and hit a pickup truck, presenting via ground in our emergency room with head injury, subluxation-avulsion injury of the thumb left, non-dislocated fracture of the Os triquetrum and Os trapeziums, distal radius fracture, fracture of metacarpals 2 and 3, and dislocated metacarpal 1 fracture (iHISS $=210$ ). After initial care by repositioning, external fixation, and osteosynthesis, a full-thickness necrosis of the radial ball of the thumb was presented. A necrectomy followed by defect reconstruction was performed. b We performed a pedicled groin flap to cover the tissue defects, and the flap was tubed around tissue defects. The groin flap was then ligated and formed. $\mathbf{c}$ After a total of 14 operations, the patient reported during follow-up his dissatisfaction with the esthetics and function of his hand. He was often stigmatized and had difficulties in public. The hand function was not acceptable to him, and he consequently changed his profession. The patient wanted amputation with a timely bionic prosthetic hand supply. Hand Bionic Score was 17, recommending a bionic supply. At removal site of the flap, there was unsatisfactory healing of the wound 
a

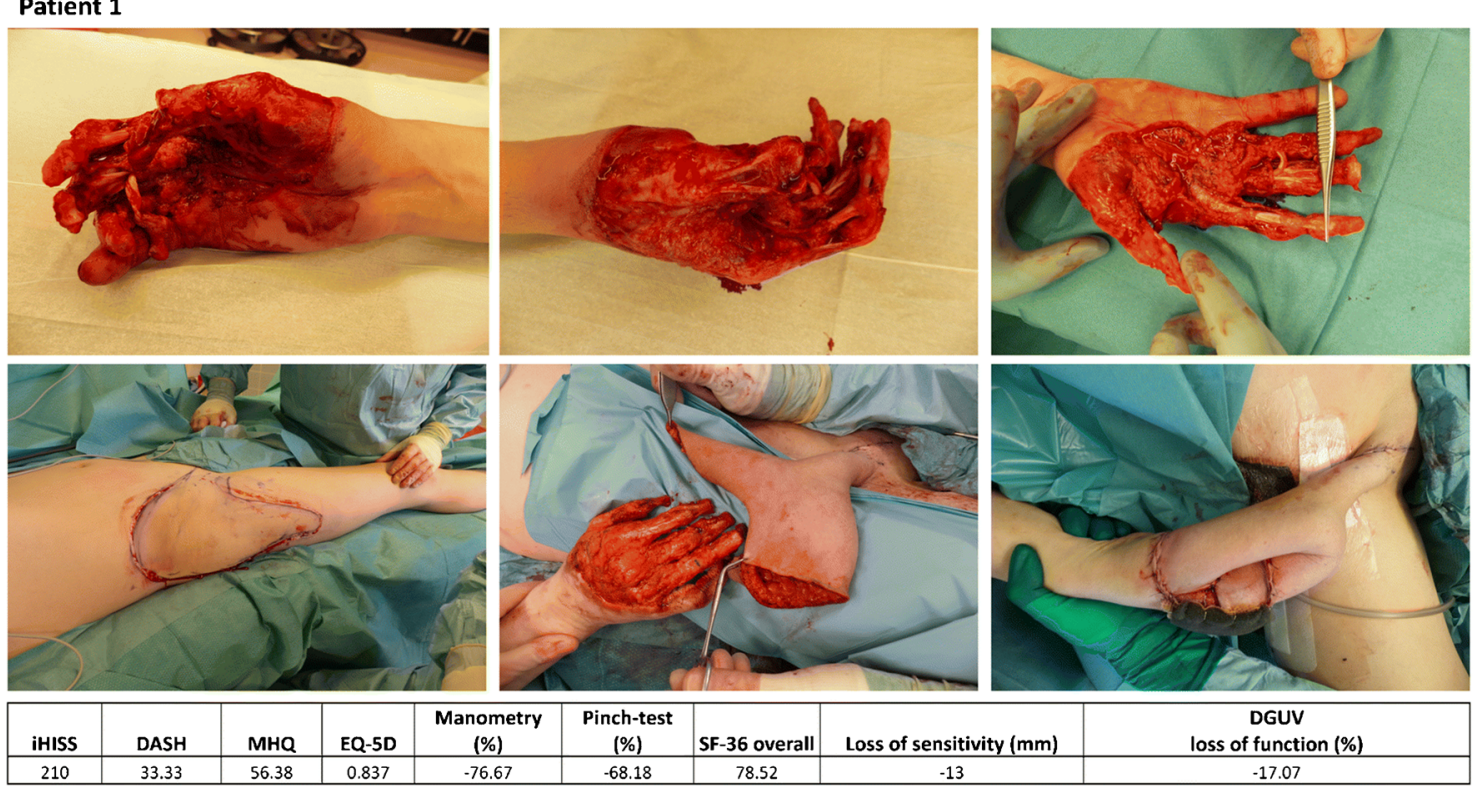

b

Patient 1
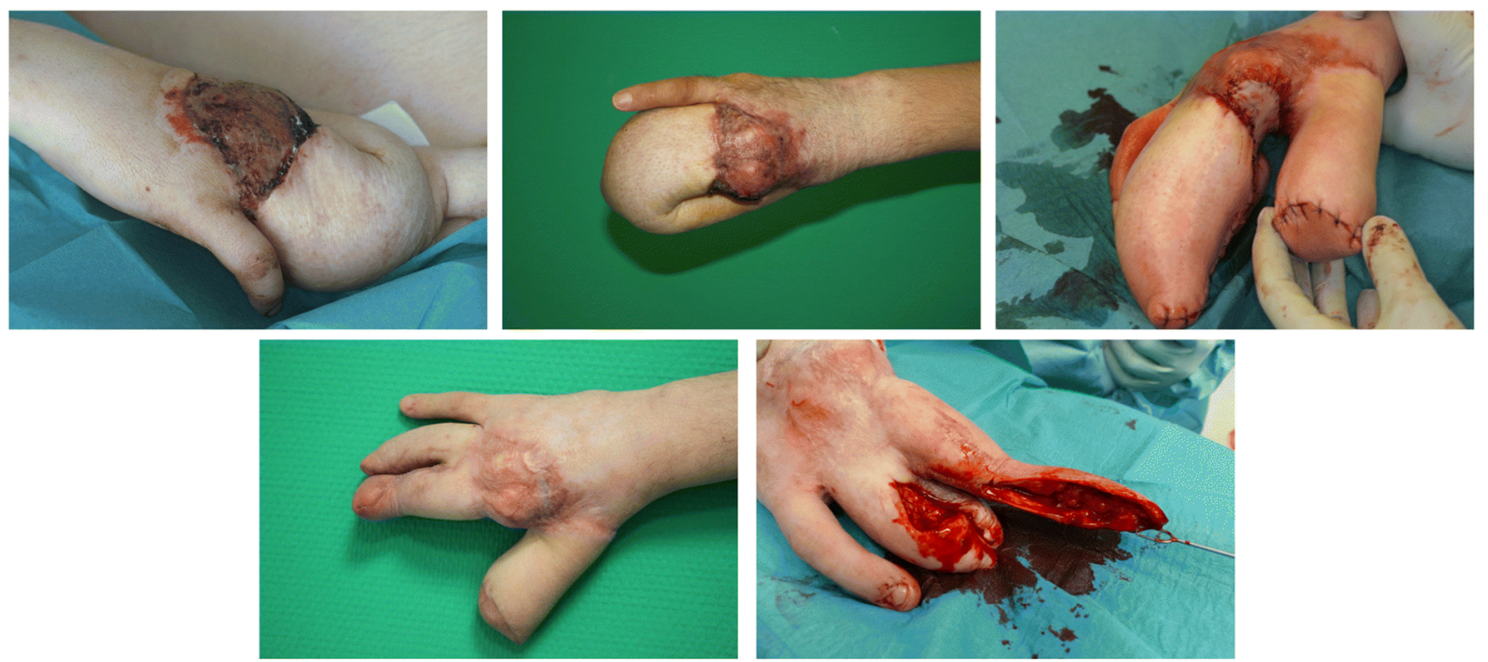

C

Patient 1
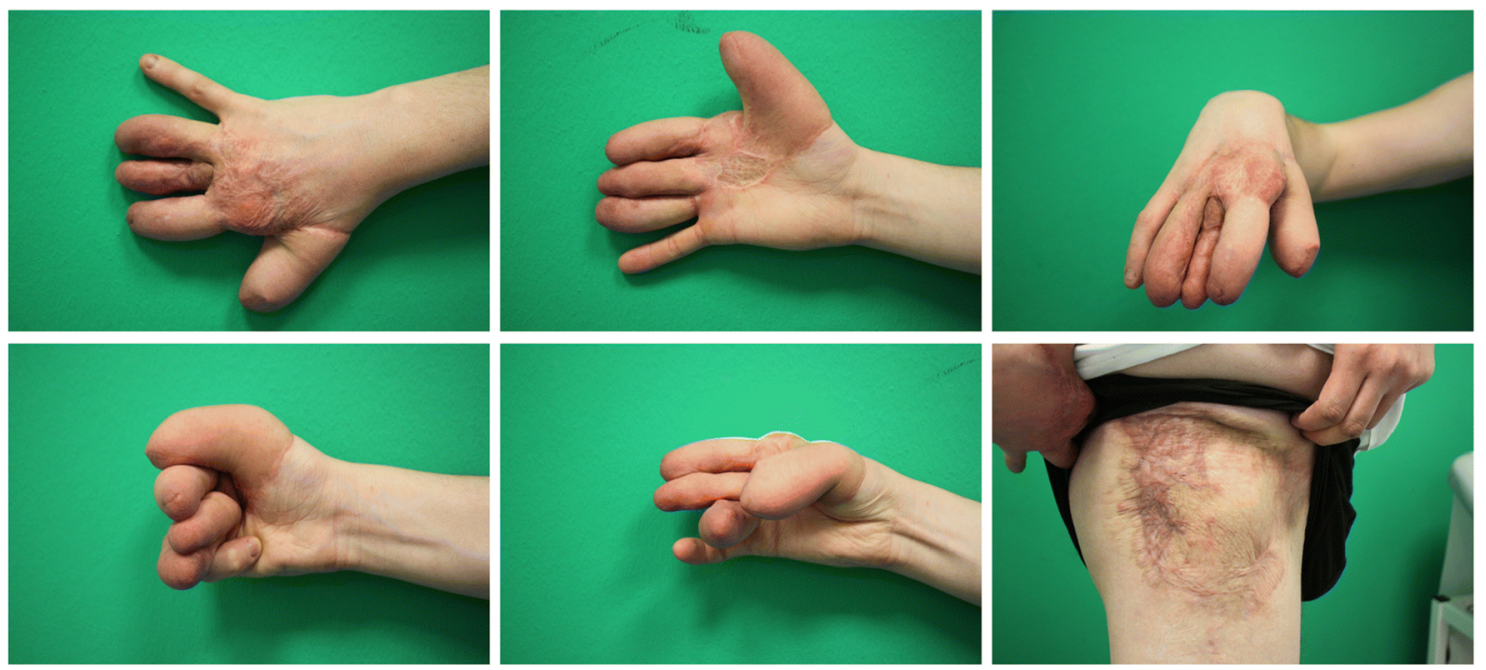
a

\section{Patient 2}
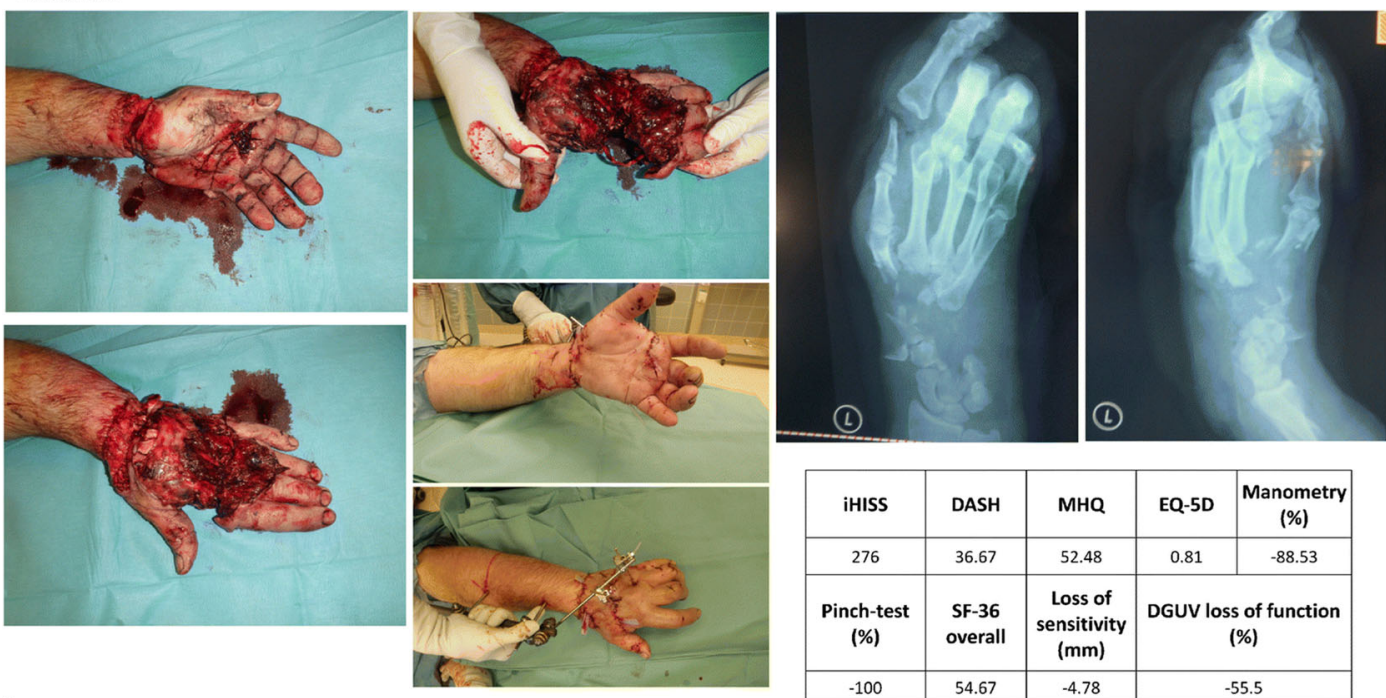

\begin{tabular}{|c|c|c|c|c|}
\hline iHISS & DASH & MHQ & EQ-5D & $\begin{array}{c}\text { Manometry } \\
\text { (\%) }\end{array}$ \\
\hline 276 & 36.67 & 52.48 & 0.81 & -88.53 \\
\hline $\begin{array}{c}\text { Pinch-test } \\
\text { (\%) }\end{array}$ & $\begin{array}{c}\text { SF-36 } \\
\text { overall }\end{array}$ & $\begin{array}{c}\text { Loss of } \\
\text { sensitivity } \\
\text { (mm) }\end{array}$ & $\begin{array}{c}\text { DGUV loss of function } \\
\text { (\%) }\end{array}$ \\
\hline-100 & 54.67 & -4.78 & \multicolumn{2}{|c|}{-55.5} \\
\hline
\end{tabular}

b

Patient 2
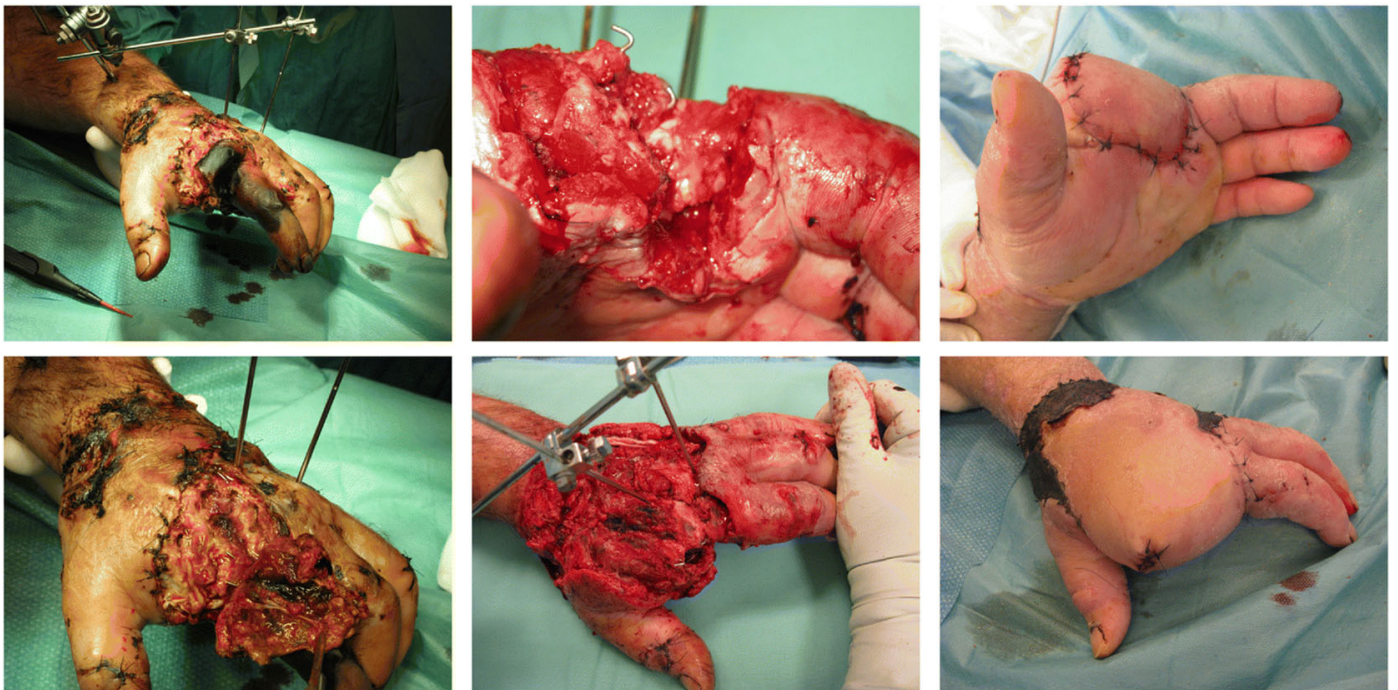

c

Patient 2
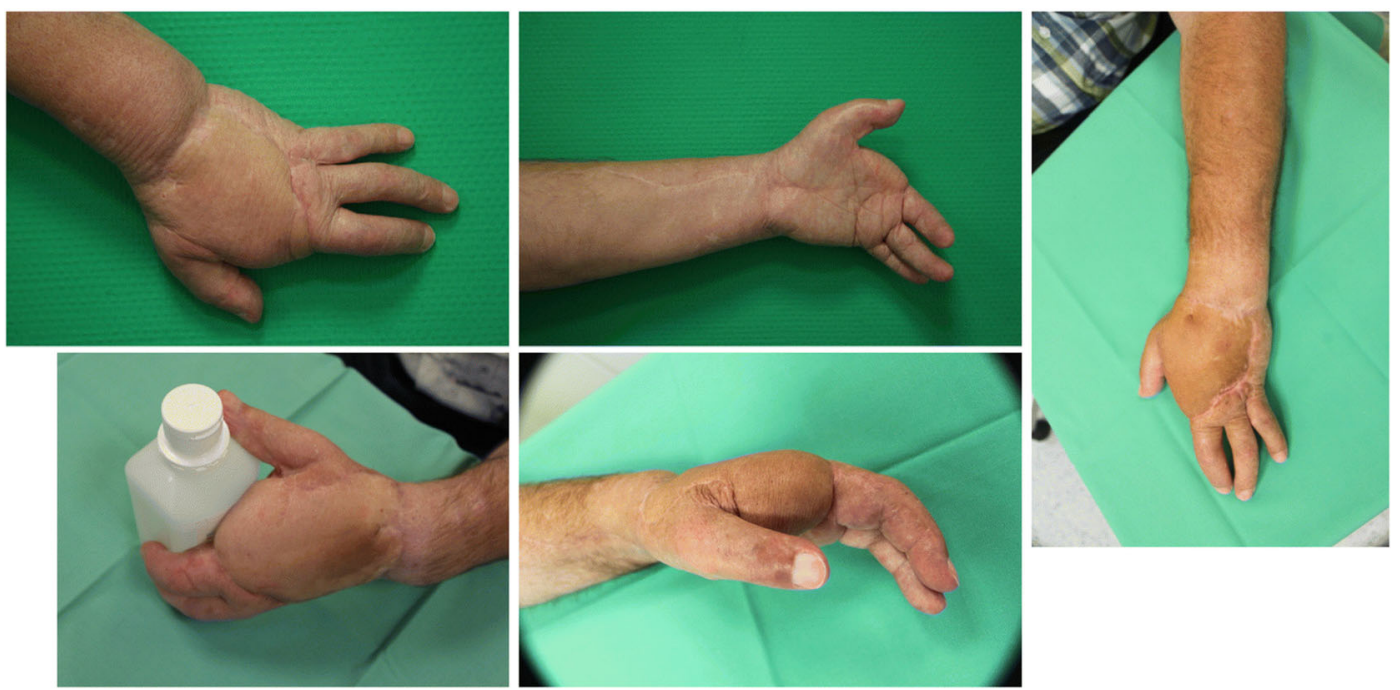
Fig. 6 Patient 2. a The patient was admitted to our emergency department after a subtotal amputation of the left hand by a turner machine accident, which shows a massive crack-crushing-cut injury of metacarpal and carpal bones (iHISS $=276$ ). After initial replantation, application of fixateur externe, and osteosynthesis with revascularization, skin necrosis of the dorsal left hand was presented. b After full-thickness inguinal skin flap transplantation, the necrosis area could be covered, but the forefinger had to be amputated. The patient developed an ulnar deviation of the long fingers, which was treated through arthrolysis and tenolysis. c After a total of 5 operations, the patient was unsatisfied with the functional result. The patient had difficulty performing simple grasping functions, severely restricting him during the day. Quality of life and hand function showed poor to very poor results. Hand Bionic Score was 19 , recommending a bionic prosthesis fitting with amputation of the nonfunctioning hand

amputation with bionic care. However, we do not yet have data to validate that early amputation and bionic prosthetic supply is better for functionality and quality of life. Especially if both upper extremities are affected, for example, it may be difficult for the patient to put on prostheses.

For bionic prosthesis supply, there are increasing concepts of optimization of signal transmission. For example, patients with serious injuries may have strong muscle destruction, which makes a clean EMG signal difficult. In such cases, concepts such as TMR are an opportunity to provide regional muscle groups with the remaining nerves of the brachial plexus and thus provide signal amplification by reinnervation [52-54]. Furthermore, complex surgical amputation techniques such as creation of an agonist-antagonist myoneural interface (AMI) [55] can improve control over prostheses by restoring muscle-tendon proprioception, such as in belowknee amputations [56, 57]. Additionally, development of regenerative peripheral nerve interfaces (RPNI) can provide reliable proportional prosthetic hand control and EMG signals $[56,58]$. RPNIs have been established to optimize signal transmission and decoding. Furthermore, control options have advanced significantly in recent years, allowing humanmachine interface pattern recognition and regression methods applied to the surface EMG to control multi-degree of freedom motor tasks intended by the user [59].

Algorithms for care of bionic prostheses are already under development and so far apply to patients with plexopathies, which lead to so-called bionic reconstruction accompanied by a multimodal concept with tech-neuro-rehabilitation programs, signal extraction, and carefully planned amputation $[60,61]$. Patients included in this study experienced massive upper limb injuries with degloving or fracture injuries, particularly sawing injuries with cracking, amputations, and significant skin soft tissue damage, as well as crush and degloving injuries from industrial rollers and heavy machinery. These injury patterns were multifunctional and spread on several functional units of the upper extremity. As shown, all available reconstruction tools were used to restore shape, function, and esthetics, yet there were marked functional limitations, resulting in patients with low quality of life. Furthermore, allografting is an alternative in cases of poor functional parameters and quality of life with Hand Bionic Scores of $>14$ points. Nevertheless, the need for life-long immunosuppression must be considered as well as a long rehabilitation period. In addition, there are no studies comparing quality of life and functionality of bionic prostheses and allografts of the upper limb.

Despite our strong results with Hand Bionic Score, it must be noted that the score may not provide reliable results in other patient cohorts. Thus, additional large, randomized, and multicenter studies are needed to control, validate, and, if necessary, further adapt the Hand Bionic Score. In addition, due to recruitment difficulties, a major weakness of this study is the non-standardized follow-up time (average. 3.67 years). Further multicenter studies that recruit patients promptly after hand injury and collect data according to a fixed follow-up scheme are needed to improve evaluation, development, and consistency of the Hand Bionic Score. Additionally, the outcome parameters are monocentric and may not be considered multi-center outcome parameters.

Patients with amputation after DIC report satisfaction with the appearance as well as average function of their prostheses. Combining these metrics indicates fair overall patient satisfaction despite fair to poor ratings of physical skills. These special cases of DIC complicate adaptation to bionic prostheses because of skin soft tissue damage and consecutive large-scale scarring from surgical recovery and secondary wound healing [24]. Patients complain primarily of uncontrollable prostheses, indicating signal transmission disorders. Due to these signal disturbances, prostheses often fail based on large-scale scarring areas. However, besides conventional direct control mechanisms based on EMG signals produced from a limited combination of muscles, new technologies such as pattern recognition can highly outperform conventional prostheses [62]. In addition, patient feedback indicates the desire for improvements in mode switching and reductions in prosthesis weight and servo volume - for example, dissatisfaction with prosthesis weight can make it difficult to attach independently and thus requires constant assistance [24]. Furthermore, for elective amputation in trauma patients, scarring problems and signal disturbances need to be analyzed.

In addition, the expected improvement in functionality through amputation and bionic care needs to be conclusively proven. However, based on current rapid developments in signal transfer, prosthetic integration with human biology, surgical therapies, technological interfacing, skeletal fixation, and sensible interfacing, outcomes, and functionalities may continue to improve 
radically [63]. For instance, a special topic is sensation of the prosthesis-while currently available prostheses need visual feedback to control movements, further development of prosthesis sensation could improve dexterity of prosthetic hands [64].

Irreversible tissue loss must also be taken into account during amputation. A decision of amputation has irreversible consequences for the patient and, as a result of complications, can be seen as a stepping stone to a wrong decision in retrospect. Phantom pain or neuropathic pain especially must be considered after amputation. For a definitive decision, continuous psychological co-treatment as well as potential hybrid adaptations with bionic prostheses for thorough detection of the hand and prosthetic function are essential. Unrealistic expectations of function and current possibilities of the technology as well as poor results in functional tests of hybrid prostheses are clear contraindications for an amputation and bionic prosthesis, despite possibly strong positive Hand Bionic Score [65].

In addition, every serious hand injury examined was highly individual and was classified according to the applied scores, but details of individual functional limitations can be significantly different. Clear formation of identical groups for follow-up was therefore difficult to implement. Based on the developed Hand Bionic Score, future randomized, controlled cohort studies in a multicenter outcome analysis of severe hand injury for early amputation and bionic prosthesis supply should be compared with conventional hand reconstruction as well elective amputation and bionic prosthesis supply after termination of surgical therapy.

\section{Conclusion}

Currently, preservation of the extremity after severe injury via necessary surgical reconstruction steps is still necessary. In cases of severe upper extremity trauma in which reconstruction does not produce the desired result, the existing limb may not only be functionless but may also be a distressing and painful burden. In these cases, advanced prosthetic technology may offer a good option to restore function. While iHISS provides reasonable assessment of early selective amputation and bionic prosthetic supply, our novel Hand Bionic Score provides measurable outcome parameters for severe hand injuries later during the course of treatment. Hand Bionic Score provides orientation for clinical decision-making regarding surgical reconstruction or bionic prosthesis supply after severe injury. The score not only considers hand function but also considers psychological markers, quality of life, patient satisfaction, and esthetics. All of these markers need to be evaluated in each patient after a severe hand injury to make the best individual clinical decision.

Authors' Contributions All authors (Dennis Werner, Seyed Arash Alawi) have read and approved the final manuscript.

All persons who meet authorship criteria are listed as authors, and all authors certify that they have participated sufficiently in the work to take public responsibility for the content, including participation in the concept, design, analysis, writing, or revision of the manuscript. Furthermore, each author certifies that this material or similar material has not been and will not be submitted to or published in any other publication.

Funding information Open Access funding enabled and organized by Projekt DEAL. The authors received no financial support for the research, authorship, and publication of this article.

\section{Compliance with ethical standards}

Conflict of interest The authors declare that there are no conflict of interest. The authors certify that they have no affiliations with or involvement in any organization or entity with any financial interest (such as honoraria. educational grants, participation in speakers' bureaus. membership, employment, consultancies, stock ownership or other equity interest, and expert testimony or patent-licensing arrangements) or nonfinancial interest (such as personal or professional relationships, affiliations, knowledge, or beliefs) in the subject matter or materials discussed in this manuscript.

Ethical approval Approval for this study was granted by the Hannover Medical School (MHH) University Ethics Committee (\#7352). Research was conducted in accordance with the 1964 Helsinki Declaration.

Informed consent All patients provided written consent for participation in the study as well as publication of data and images.

Open Access This article is licensed under a Creative Commons Attribution 4.0 International License, which permits use, sharing, adaptation, distribution and reproduction in any medium or format, as long as you give appropriate credit to the original author(s) and the source, provide a link to the Creative Commons licence, and indicate if changes were made. The images or other third party material in this article are included in the article's Creative Commons licence, unless indicated otherwise in a credit line to the material. If material is not included in the article's Creative Commons licence and your intended use is not permitted by statutory regulation or exceeds the permitted use, you will need to obtain permission directly from the copyright holder. To view a copy of this licence, visit http://creativecommons.org/licenses/by/4.0/.

\section{References}

1. Oleske DM, Hahn JJ (1992) Work-related injuries of the hand: data from an occupational injury/illness surveillance system. J Community Health 17(4):205-219

2. Sorock GS, Lombardi DA, Hauser RB, Eisen EA, Herrick RF, Mittleman MA (2002) Acute traumatic occupational hand injuries: type, location, and severity. J Occup Environ Med 44(4):345-351

3. Hussmann J, Kucan JO, Russell RC, Bradley T, Zamboni WA (1995) Electrical injuries - morbidity, outcome and treatment rationale. Burns 21(7):530-535 
4. Zhang G, Ju J, Jin G, Tang L, Fu Y, Hou R (2016) Replantation or revascularization for the treatment of hand degloving injuries. $\mathrm{J}$ Plast Reconstr Aesthet Surg 69(12):1669-1675

5. von Schroeder HP, Botte MJ (1998) Crush syndrome of the upper extremity. Hand Clin 14(3):451-456

6. Neumeister M, Hegge T, Amalfi A, Sauerbier M (2010) The reconstruction of the mutilated hand. Semin Plast Surg 24(1):77-102

7. Chim H, Maricevich MA, Carlsen BT, Moran SL, Salgado CJ, Wei FC, Mardini S (2013) Challenges in replantation of complex amputations. Semin Plast Surg 27(4):182-189

8. Pet MA, Ko JH (2019) Indications for replantation and revascularization in the hand. Hand Clin 35(2):119-130

9. Kamarul T, Mansor A, Robson N, Albusaidi SH, Suhaeb AM, Samsudin EZ (2018) Replantation and revascularization of amputated upper limb appendages outcome and predicting the factors influencing the success rates of these procedures in a tertiary hospital: an 8-year retrospective, cross-sectional study. J Orthop Surg (Hong Kong) 26(1) 2309499017749983

10. Sherman R (2002) To reconstruct or not to reconstruct? N Engl J Med 347(24):1906-1907

11. Gilbert SE (1996) Implications of severe trauma to the hand. Prof Nurse 11(6):368-370

12. Klapheke M (1999) Transplantation of the human hand: psychiatric considerations. Bull Menn Clin 63:159-173

13. Pulvertaft RG (1975) Psychological aspects of hand unjuries. Hand 7(2):93-103

14. Meyer B, Asbrock F (2018) Disabled or cyborg? How bionics affect stereotypes toward people with physical disabilities. Front Psychol 9:2251

15. Alawi SA, Werner D, Könneker S, Vogt PM, Jokuszies A (2018) Quality of life and reconstructive surgery efforts in severe hand injuries. Innov Surg Sci 3(2):147-156

16. Brown PW (1996) Body and soul. J Hand Ther 9(3):201-202

17. Dogu B, Kuran B, Sirzai H, Sag S, Akkaya N, Sahin F (2014) The relationship between hand function, depression, and the psychological impact of trauma in patients with traumatic hand injury. Int $\mathrm{J}$ Rehabil Res 37(2):105-109

18. Ramel E, Rosberg HE, Dahlin LB, Cederlund RI (2013) Return to work after a serious hand injury. Work 44(4):459-469

19. Hu J, Jiang Y, Liang Y, Yu IT, Leng H, He Y (2014) Predictors of return to work and duration of absence following work-related hand injury. Int J Inj Control Saf Promot 21(3):216-223

20. Shi Q, Sinden K, MacDermid JC, Walton D, Grewal R (2014) A systematic review of prognostic factors for return to work following work-related traumatic hand injury. J Hand Ther 27(1):55-62

21. Gustafsson M, Ahlström G (2004) Problems experienced during the first year of an acute traumatic hand injury - a prospective study. J Clin Nurs 13(8):986-995

22. Grunert BK, Smith CJ, Devine CA, Fehring BA, Matloub HS, Sanger JR et al (1988) Early psychological aspects of severe hand injury. J Hand Surg Br 13(2):177-180

23. Alawi SA, Ipaktchi R, Mett TR, Kuhbier JW, Neubert N, Strauss S (2019) Survey on the state of knowledge of upper limb bionic prosthetic options in German hospitals - a multicenter and multidiscipline inquiry. GMS Ger Plast Reconstr Aesthet Surg 9 Doc01 (20190227)

24. Werner D, Alawi SA (2019) Four extremity amputation and bionic prosthesis supply after disseminated intravascular coagulation: a follow-up on functionality and quality of life after bionic prosthesis supply. World J Plast Surg 8(2):146-162

25. Semasinghe CL, Madusanka DGK, Ranaweera RKPS, Gopura RARC (2019) Transradial prostheses: trends in development of hardware and control systems. Int J Med Robot 15(1):e1960

26. Bergmeister KD, Hader M, Lewis S, Russold MF, Schiestl M, Manzano-Szalai K, Roche AD, Salminger S, Dietl H, Aszmann OC (2016) Prosthesis control with an implantable multichannel wireless electromyography system for high-level amputees: a large-animal study. Plast Reconstr Surg 137(1):153-162

27. Salminger S, Sturma A, Hofer C, Evangelista M, Perrin M, Bergmeister KD et al (2019) Long-term implant of intramuscular sensors and nerve transfers for wireless control of robotic arms in above-elbow amputees. Sci Robot 4(32):eaaw6306

28. Salminger S, Sturma A, Roche AD, Mayer JA, Gstoettner C, Aszmann OC (2019) Outcomes, challenges and pitfalls after targeted muscle reinnervation in high level amputees. Is it worth the effort? Plast Reconstr Surg

29. Bumbaširević M, Lešić A, Palibrk T, Georgescu AV, Matei IR, Vučetić Č et al (2019) What microsurgeon, orthopaedic and plastic surgeon should know about bionic hand. Injury S0020-1383(19): 30667-30669

30. Geethanjali P (2016) Myoelectric control of prosthetic hands: stateof-the-art review. Med Devices (Auckl) 9:247-255

31. Amsuess S, Vujaklija I, Goebel P, Roche AD, Graimann B, Aszmann OC, Farina D (2016) Context-dependent upper limb prosthesis control for natural and robust use. IEEE Trans Neural Syst Rehabil Eng 24(7):744-753

32. Deutsche Gesetzliche Unfallversicherung - Messblatt für obere Gliedmaßen (nach der Neutral - 0 - Methode). www.dguv.de/ medien/formtexte/aerzte/f 4222/f4222.doc Last accesed Aug 01, 2019

33. Brazier JE, Harper R, Jones NM, O'Cathain A, Thomas KJ, Usherwood T, Westlake L (1992) Validating the SF-36 health survey questionnaire: new outcome measure for primary care. BMJ 305(6846):160-164

34. Herdman M, Gudex C, Lloyd A, Janssen M, Kind P, Parkin D, Bonsel G, Badia X (2011) Development and preliminary testing of the new five-level version of EQ-5D (EQ-5D-5L). Qual Life Res 20(10): 1727-1736

35. Hudak PL, Amadio PC, Bombardier C (1996) Development of an upper extremity outcome measure: the DASH (disabilities of the arm, shoulder, and head) [corrected]. Am J Ind Med 29(6):602-608

36. Chung KC, Pillsbury MS, Walters MR, Hayward RA (1998) Reliability and validity testing of the Michigan hand outcomes questionnaire. J Hand Surg Am 23(4):575-587

37. Campbell DA, Kay SPJ (1996) The hand injury severity scoring system. J Hand Surg Br 21(3):295-298

38. Saxena P, Cutler L, Feldberg L (2004) Assessment of the severity of hand injuries using 'hand injury severity score', and its correlation with the functional outcome. Injury 35(5):511-516

39. Matsuzaki H, Narisawa H, Miwa H, Toishi S (2009) Predicting functional recovery and return to work after mutilating hand injuries: usefulness of Campbell's hand injury severity score. J Hand Surg Am 34(5):880-885

40. Lin DCY, Chang JH, Shieh SJ, Tsai FH, Lee YL (2012) Prediction of hand strength by hand injury severity scoring system in hand injured patients. Disabil Rehabil 34(5):423-428

41. Youden WJ (1950) Index for rating diagnostic tests. Cancer 3(1): 32-35

42. Medling BD, Bueno RA Jr, Russell RC, Neumeister MW (2007) Replantation outcomes. Clin Plast Surg 34(2):177-185 vii-viii

43. Aszmann OC, Vujaklija I, Roche AD, Salminger S, Herceg M, Sturma A, Hruby LA, Pittermann A, Hofer C, Amsuess S, Farina D (2016) Elective amputation and bionic substitution restore functional hand use after critical soft tissue injuries. Sci Rep 6:34960

44. Cone J, Hueston JT (1974) Psychological aspects of hand injury. Med J Aust 1(4):104-108

45. Grunert BK, Devine CA, Matloub HS, Sanger JR, Yousif NJ (1988) Flashbacks after traumatic hand injuries: prognostic indicators. J Hand Surg Am 13(1):125-127

46. Grunert BK, Matloub HS, Sanger JR, Yousif NJ, Hettermann S (1991) Effects of litigation on maintenance of psychological symptoms after severe hand injury. J Hand Surg Am 16(6):1031-1034 
47. Grunert BK, Devine CA, Matloub HS, Sanger JR, Yousif NJ, Anderson RC, Roell SM (1992) Psychological adjustment following work-related hand injury: 18-month follow-up. Ann Plast Surg 29(6):537-542

48. Himmelstein JS, Feuerstein M, Stanek EJ 3rd, Koyamatsu K, Pransky GS, Morgan W et al (1995) Work-related upper-extremity disorders and work disability: clinical and psychosocial presentation. J Occup Environ Med 37(11):1278-1286

49. Kovacs L, Grob M, Zimmermann A, Eder M, Herschbach P, Henrich G, Zimmer R, Biemer E, Papadopulos NA (2011) Quality of life after severe hand injury. J Plast Reconstr Aesthet Surg 64(11):1495-1502

50. Weddington WW Jr, Segraves KB, Simon MA (1985) Psychological outcome of extremity sarcoma survivors undergoing amputation or limb salvage. J Clin Oncol 3(10):1393-1399

51. Mayer A, Kudar K, Bretz K, Tihanyi J (2008) Body schema and body awareness of amputees. Prosthetics Orthot Int 32(3):363-382

52. Merad M, de Montalivet É, Touillet A, Martinet N, Roby-Brami A, Jarrassé N (2018) Can we achieve intuitive prosthetic elbow control based on healthy upper limb motor strategies? Front Neurorobot 12: 1

53. Adewuyi AA, Hargrove LJ, Kuiken TA (2017) Resolving the effect of wrist position on myoelectric pattern recognition control. J Neuroeng Rehabil 14(1):39

54. Benatti S, Milosevic B, Farella E, Gruppioni E, Benini L (2017) A prosthetic hand body area controller based on efficient pattern recognition control strategies. Sensors (Basel):17(4)

55. Srinivasan SS, Diaz M, Carty M, Herr HM (2019) Towards functional restoration for persons with limb amputation: a dual-stage implementation of regenerative agonist-antagonist myoneural interfaces. Sci Rep 9(1):1981

56. Clites TR, Carty MJ, Ullauri JB, Carney ME, Mooney LM, Duval JF et al (2018) Proprioception from a neurally controlled lowerextremity prosthesis. Sci Transl Med:10(443)

57. Clites TR, Herr HM, Srinivasan SS, Zorzos AN, Carty MJ (2018) The Ewing amputation: the first human implementation of the agonist-antagonist myoneural interface. Plast Reconstr Surg Glob Open 6(11):e1997

58. Frost CM, Ursu DC, Flattery SM, Nedic A, Hassett CA, Moon JD, Buchanan PJ, Brent Gillespie R, Kung TA, Kemp SWP, Cederna PS, Urbanchek MG (2018) Regenerative peripheral nerve interfaces for real-time, proportional control of a Neuroprosthetic hand. J Neuroeng Rehabil 15(1):108

59. Nielsen JL, Holmgaard S, Jiang N, Englehart K, Farina D, Parker P (2009) Enhanced EMG signal processing for simultaneous and proportional myoelectric control. Conf Proc IEEE Eng Med Biol Soc 2009:4335-4338

60. Aman M, Festin C, Sporer ME, Gstoettner C, Prahm C, Bergmeister KD, Aszmann OC (2019) Bionic reconstruction: restoration of extremity function with osseointegrated and mindcontrolled prostheses. Wien Klin Wochenschr

61. Hruby LA, Sturma A, Mayer JA, Pittermann A, Salminger S, Aszmann OC (2017) Algorithm for bionic hand reconstruction in patients with global brachial plexopathies. J Neurosurg 127(5): 1163-1171

62. Hargrove LJ, Miller LA, Turner K, Kuiken TA (2017) Myoelectric pattern recognition outperforms direct control for transhumeral amputees with targeted muscle reinnervation: a randomized clinical trial. Sci Rep 7(1):13840

63. Aman M, Sporer ME, Gstoettner C, Prahm C, Hofer C, Mayr W, Farina D, Aszmann OC (2019) Bionic hand as artificial organ: current status and future perspectives. Artif Organs 43(2):109-118

64. Okorokova EV, He Q, Bensmaia SJ (2018) Biomimetic encoding model for restoring touch in bionic hands through a nerve interface. J Neural Eng 15(6):066033

65. Aszmann OC, Roche AD, Salminger S, Paternostro-Sluga T, Herceg M, Sturma A, Hofer C, Farina D (2015) Bionic reconstruction to restore hand function after brachial plexus injury: a case series of three patients. Lancet 385(9983):2183-2189

Publisher's note Springer Nature remains neutral with regard to jurisdictional claims in published maps and institutional affiliations. 